\title{
Role of Business Models in Funding the Biotech Industry: Global Trends and Challenges for Cuban Biotechnology
}

\author{
Einard Blanco-García MS
}

\begin{abstract}
Forty-three years after it was founded, with billions of dollars invested, the global biotech industry is still not positioned as a mature low-risk sector for the international investor community. Despite the clear commercial success of a number of leading companies and overall growth of the industry's revenues, most biotech companies are not profitable and many fail to overcome the formidable barrier constituted by the high cost of the sector's research and development. However, over the last four years, visible signs of change have appeared, which could be harbingers of an approaching turning point in this trend.
\end{abstract}

This article analyzes the historic background of the biotech industry's business models and corporate structures, as well as

\section{INTRODUCTION}

With global sales of US\$188 billion in 2017 and 316 commercially licensed products in the United States and Europe by mid-2018, biotechnology is one of the world's fastest growing industries today.[1]

The biotech industry has had a significant impact on biomedical sciences innovation, diagnosis and treatment of chronic noncommunicable diseases, evolution of government health policies, and the risk-management model for financial operations in capital markets.[2]

Despite this progress, the biopharmaceutical industry still shows signs of organizational immaturity, hampering its definitive economic takeoff. Indications of this sluggish trajectory are the high indices of uncertainty and financial volatility compared to more established sectors (such as the pharmaceutical industry itself). [3] Over the last four years, however, significant changes have been emerging in the corporate architecture and business models in which the industry's key actors operate, making it possible to envision a path toward higher performance levels.

This article examines the basic determinants of these changes and discusses the challenges and opportunities they present for development of Cuba's biotech industry.

The global biotech boom: science as business According to Pisano,[4] the concept of science as business arose in 1976

IMPORTANCE This paper presents an overview of the evolution of the biotech industry's financial framework. It also proposes strategic guidelines to reformulate Cuban research and development (R\&D) programs in the sector to minimize risk and facilitate access to sources of capital. their impact on the industry's financial framework. It examines recent changes implemented by the sector's main actors-including young startups, venture capital funds and big pharma companies - to mitigate financial risk associated with development of new biotechnology products.

Finally, it discusses the challenges and opportunities that these tendencies entail for Cuban biotechnology development and proposes adoption of business policies more tolerant of the financial risk inherent in this sector, as a condition for attracting venture capital.

KEYWORDS Biotechnology, fund raising, risk management, entrepreneurship, Cuba

when young, up-and-coming investor Robert Swanson joined University of California professor Herbert Boyer to found Genentech, the world's first biotech firm. Pisano posed that, in addition to demonstrating that recombinant DNA could be applied successfully to industrial-scale in-vitro production of human proteins for use as medicines, Genentech created a model to monetize intellectual property that enabled expansion of the biotech industry's potentialities, situating it by the late 1990s as one of the world's fastest-growing economic sectors.

Pisano posited that this new model was based on three interrelated pillars:

- technology transfer from universities to the private sector, creating new firms instead of licensing technologies to traditional pharmaceutical companies;

- access to capital markets (public or private) to finance the technology's initial development phases, mainly clinical research, and to compensate incubator company founders for the initial risk they assumed; and

- a know-how market in which, once clinical efficacy was demonstrated, young firms license or sell their intellectual property to established pharmaceutical firms in exchange for additional financing to once again enable reimbursement for founders and venture capital investors.[4]

The model's structure was largely based on the Silicon Valley paradigm, which had worked so well to commercially channel the burgeoning innovative wave of the informatics/communications sector (software, computers, semiconductors, cellphones, Internet, online services, etc.).

Prior to founding Genentech, science and business operated in separate spheres of influence. Basic medical sciences were the exclusive pursuit of universities and research centers, while pharmaceutical companies invested only in incremental improve- 
ments in the innovations acquired from those institutions. In 1978 , Genentech licensed the rights to manufacture and market recombinant insulin to the company Eli Lilly. Under the agreement, Eli Lilly would finance product development and pay Genentech royalties on sales.[5] This was the first time a big pharma transnational acquired technology protected as intellectual property of another for-profit company.

Genentech's successful public offering in 1980 also showed for the first time that a company with no products in the market, no income and no earnings was capable of attracting investment capital based on expectation of future growth. This was the start of the market's recognition of the potential of intangible assets (patents and know-how) to generate future earnings in the legal context provided by guarantees of commercial exclusivity for patent-protected products. This success fostered the market's perception that biotechnology was capable of converting science into business.

In the 1980s and 1990s, the biotech sector appeared to offer a solution to the scientific productivity crisis suffered by the large transnational pharmaceutical companies. In the late 1990s, big pharma tried in vain to recuperate from the financial imbalance caused by income lost from blockbuster products (often products with annual sales in the billions of dollars) due to patent expiration and new products entering the market sustained by increased R\&D spending.[2] Biotech firms offered presumed advantage in new product development, given their smaller size and greater scientific specializations, as compared to the significant bureaucracy and vertical structuring inherent to big pharma.

Inspired by Genentech's success, pharmaceutical firms enthusiastically invested in biotechnology, facilitating emergence of firms such as Amgen, Biogen, Cetus, Chiron, Genzyme and Idec.[2]

Perception of superior scientific productivity expected from the biotech sector, compared with that of the pharmaceutical industry, was reinforced by the significant advances in genomics, proteomics and combinatorial chemistry starting in the 1990s, predictors of greater efficacy in candidate products' development and selection. Finally, the indisputable commercial success of hormone replacement therapies (insulin, human growth hormone, coagulation factors and erythropoietin)[2] appeared to validate the idea that biotechnology would increase R\&D projects' probability of success with less risk to investors, and that these elements together would unleash the industry's economic potential.

Once biotech's "paradigm of promise" was introduced, it appeared that funding sources would not pose a problem. It may be useful at this point to review the financing mechanisms for biotech's intensive R\&D spending.

The industry's financial engine and death valley Emergence of biotech firms as centers for innovative product development, outside of universities, limited access to government funding. Young prototypical entrepreneurs were forced to seek alternative sources in the capital market, laying the groundwork for a new paradigm in which venture capital investors covered the growing financial needs of product clinical development.[6] Figure 1 summarizes biotech's capital sources according to each R\&D project's development stage in the product portfolio.
These funds invest in biotech firms with promising R\&D projects (already demonstrated in initial trials) whose significant innovations could make a big splash in the market. In exchange, investors participate as shareholders in the firms, with the expectation of increased stock values, permitting subsequent sales of their shares at higher prices. In 2014, Ford and Nelsen[7] identified the following main sources of biotech capital:

- Family and friends: Typically, these include members of the founding entrepreneurs' inner circle. They provide seed capital to establish incubator companies. They do not seek to generate profits, but rather are motivated simply by the desire to help a relative or friend starting up a new high-risk business venture. Usually, these investments are only in the tens of thousands of US dollars.

- Angels: Angel investors and super-angel investors invest in companies in very early product development stages, usually in the preclinical research phase. Since this is a highly risky stage, appearance of a fund interested in investing is perceived as a gift from heaven, hence the name "angel." Angels may invest hundreds of thousands of dollars, but they decide their investments based on considerable scientific and business acumen, in addition to connections that enable them to contribute more to the target company's growth than the precise amount invested. Many are successful entrepreneurs themselves with experience funding other incubators.

- Foundations and patient groups: These nonprofit organizations that promote advances in the fight against specific diseases, commonly invest in early development phases. Accessing these funds requires a clear connection between the organization's area of interest and the innovation promoted by the incubator.

- Venture capitalists: These companies specialize in financial management of funds from different sources (personal, business, banks, pensions, etc.). They may invest in a wide range of economic sectors to diversify risk, but some specialize in biotechnology. They invest in startup companies in early development phases when stock market indicators are favorable. They move investments toward later-stage companies (with less risk) in times of financial crisis. They invest tens of millions of dollars per company.

- Federal government agencies: These include a wide range of agencies that foster public policies through investment in development programs (local, national and international).

- Family funds: These are companies that manage funds of wealthy individuals and families, usually including contributions of US\$100 million or more per member. They invest in all stages of a biotech firm's development.

- Corporate venture capital: These are investment funds created by pharma giants mainly since the late 1990s. They emerged after the wave of patent expirations resulting in a crisis of low scientific productivity that intensified in the early 2000s. The new investments enabled big pharma companies to extend their options of control over young biotech firms' portfolios of innovative products, thus avoiding costs associated with expansion of their own R\&D programs and the corresponding burden of their internal bureaucracies. 
Figure 1: Sources of capital for biotechnology, by R\&D project development phase

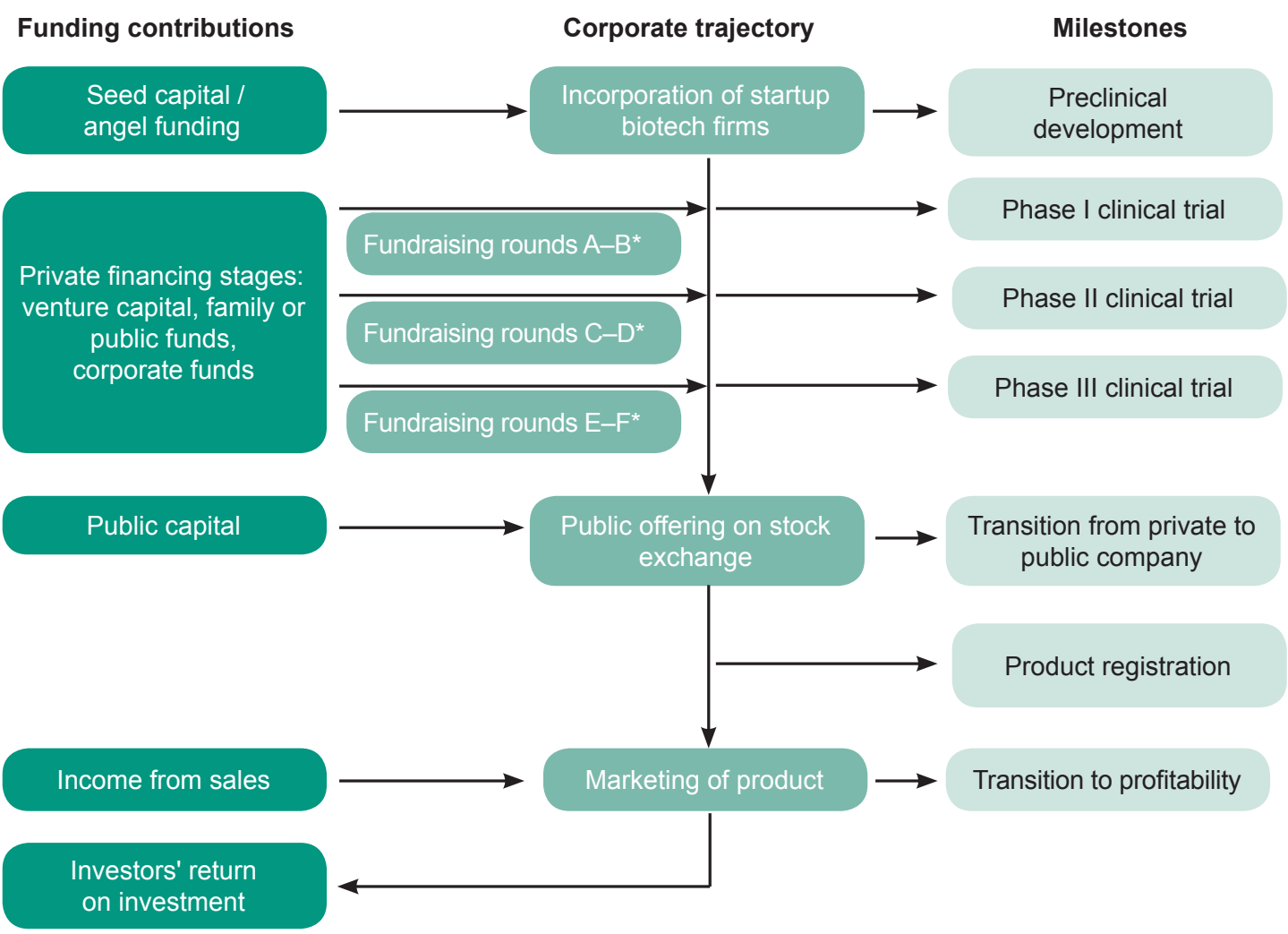

${ }^{*}$ A-B: fundraising rounds for Phase I clinical trials; C-D: fundraising rounds for Phase II clinical trials; E-F: fundraising rounds for Phase III clinical trials

Biotech firms' bold approach to securing alternative funding sources, as occurred in Silicon Valley, enabled several to take off, including Amgen, Genentech (now part of Roche), Biogen and Genzyme (now part of Sanofi). They now have several products with sales above US\$1 billion and can afford the luxury of financing their own growing R\&D project portfolio.[2]

Just over 40 years after the biotech industry's founding, however, only a small fraction of its companies have become profitable and as a whole the sector operates with negative profitability indicators.[1] Moreover, globally, about $50 \%$ of biotech companies operate with liquidity levels sufficient for less than two years of survival.[8]

In its first 20 years, the biotech sector appeared to successfully apply the Silicon Valley model for attracting funding sources to bring its innovations to market. Unlike the information and communications technology (ICT) sector, however, with its 2- to 3-year development cycles, the biotech product cycle is 10 to 12 years and-according to various sources-requires investments that range from almost US\$650 million to US\$1.8 billion. $[9,10]$ The lion's share of these considerable development expenses is explained by the high cost of conducting clinical trials required to prove product efficacy and safety for human use.

In addition, government regulatory agencies continually tighten the requirements for approving registrations and conducting clinical trials, further boosting costs. The high cost of clinical development has created an insurmountable hurdle for the majority of biotech companies. They must often sacrifice potential candidates from their project portfolio due to the difficulty of financing them. A leading project's failure to demonstrate clinical efficacy and/or safety can send a business into bankruptcy. Both the highest costs and the highest probability of failure are concentrated in this product development phase, when substantial resources and time have already been invested in the project. This phase is referred to as "death valley." So then, what factors determine profitability in biotechnology?

Innovation and uncertainty: financial risk in development of biotech products Venture capital investors usually operate with a three- to fouryear timeline from initial investment to return of capital with earnings. In the case of clinical development, the more extended timeline does not allow for balancing investors' interest in short-term profits with biotech companies' goal of getting their products to the marketing phase, especially when the financial costs are so high and the likelihood of success so uncertain.

Two of the most rigorous recent studies[11,12] estimated that less than one in ten products manage to pass all phases of clinical development and to reach market $(9.6 \%$ and $6.9 \%$ in the studies). The greatest likelihood of failure occurs in Phase II clinical trials: approximately one in three products succumbs in this stage $(30.7 \%$ and $38.2 \%$, according to the studies) when products must first prove their efficacy in humans (Phase I trials demonstrate product safety, while Phase III confirm safety/ efficacy in a larger population).

Despite the scientific and technological advances made in biotechnology, data confirm that lingering uncertainties hinder the capacity to predict a product's success in its interaction with complex biological systems. The primary challenge lies in designing diagnostic and classification systems that can better identify patients who can potentially benefit from a given treatment (as occurs in personalized medicine).

The additional risk factor associated with the greater volatility of investing in biotechnology as compared to other sectors[3] has propelled venture capital funding toward greater specialization in selecting assets in which to invest and greater diversification of investments as a way to compensate for po- 
tential failures. Fortunately, the capital market's perception of biotechnology's potential to generate high rates of return on investments remains high, especially for the most specialized investors.[13]

Assessing $\mathbf{4 0}$ years of biotechnology development: the risk does not justify the investment $A$ study of economic performance of all publicly traded biotech companies (627) in 2017 concluded that these companies generated revenues of US $\$ 160.6$ billion (85\% of total sales in the sector) and R\&D spending of US\$49.3 billion (30.7\% of total income). These figures confirm the aforementioned intensity of R\&D spending. [13] However, the top 30 companies account for more than $80 \%$ of revenues (US $\$ 134$ billion), illustrating the high concentration of earnings in the industry. By the close of 2017, these 30 companies employed over 145,000 workers worldwide, more than the 101,000 workers employed by the remaining (public) biotech firms.[13] Compilation of data from all public companies (large and small) confirms that the sector operated with a negative rate of return during 2017 (total loss of almost US\$ 2.7 billion).[13] As reported by Nature Biotechnology, globally the industry did not turn a profit until 2018, with a total net revenue of US\$345 million.[14]

These data reinforce the hypothesis set forth by Pisano in 2006[4] on the flawed structure of the industry. According to Pisano, the prevailing organizational structure has constrained it and prevented biotech from untying the Gordian knots keeping it from maturing as an industry:

- High risk: As an industry, biotechnology operates under high levels of inherent risk, due to the deep and systematic uncertainty rooted in the limited knowledge of human biological processes and systems.

- Poor integration: A medication's development process cannot be broken down into its components; the disciplines involved must coordinate and work closely together. The structure of small and highly specialized incubator companies presents an obstacle to this principle.

- Limited learning: A good portion of the knowledge generated by the disciplines involved in the biotech sector is implicit and intuitive, which complicates the necessary task of coordinating collective learning.

Pisano argues that for most industries' R\&D, basic technological feasibility is not a problem, since efforts and resources are invested in developing primary concepts of known technical feasibility. Industrial designers, for example, can address engineering problems concerning car parts, confident that the car will run when the process is complete. In biotechnology, however, the industry faces an added challenge: to attain confidence involves a long and uncertain trial-and-error process in which instinct and individual experience continue to carry considerable weight.

Will it be possible, then, to tip the balance toward greater certainty in the development of this burgeoning but risky industry?

New emerging model: mitigating the risk In the three-year period from 2015 to 2018, biotechnology took a major leap forward in its capacity to attract venture capital. For the first time in its history, overall venture capital investments in 2015 sur- passed the barrier of US\$6 billion, reaching over US\$10 billion, and not falling below US\$8 billion in more recent years.[15]

Although fluctuations in capital markets are the rule and not the exception, the shift in the industry's capacity to convert science into business does not appear to be circumstantial. There is evidence of improved interactions between key stakeholders in the industry's value chain that may offer responses to the contradictions outlined by Pisano.[4] These indications are summarized as follows:

The biotech company Progress in the field of personalized medicine has helped optimize the patient selection process for new therapies,[16] resulting in increased benefits exhibited by these products in early clinical phases, thus reducing time, development costs and risk to investors. For 20 years, from 1995 to 2014, the number of biological products in the USA and Europe (registered in average 5-year periods) hovered around 54 to 60 . In the 3.5 years from January 2015 to July 2018, 112 new biological products were registered.[1] True, this period coincided with the emergence of biosimilars, which increased the number of registrations by $59 \%$ compared to the previous 5-year period (2010-2014), but novel products saw similar growth (52\%). Examples of this new reality include the drugs Keytruda, Opdivo, Kymriah and Yescarta (all approved by the FDA and EMA with Phase II clinical results). The first two, registered in 2017 , achieved global sales the same year of US $\$ 3.8$ billion and US\$.79 billion, respectively.[1]

An analysis of all drugs registered between 2006 and 2015 illustrates the importance of appropriate patient selection, based on personalized medicine research, to mitigate the risk of failures in clinical development.[11] Data show that from the preclinical research stage, use of biomarkers during clinical development can triple the likelihood of a product's entry into the market (from $8.4 \%$ to 25\%).[11] Recent advances in big data management and artificial intelligence can further reinforce this trend.

Venture capital funds In 2013, nine of the ten companies that raised the most capital in their initial public offerings had products in Phase III clinical trials already on the market. In 2017, six of the first ten had products in Phase I or Phase II.[15] In stark contrast with the past, these figures show the market's perception of the increasing value of companies with portfolios of innovative, early-stage development projects. They also reveal a capacity to ensure attractive returns for shareholders.

Greater investor interest in exploring businesses in early development stages is proof of the growing maturity of investment funds, which now often have executives from the biotech sector who have deeper scientific knowledge and are more capable of evaluating investment risks.

Several of these funds (including Third Rock Ventures, ARCH Venture Partners, Flagship Pioneering and Fidelity Biosciences) have abandoned the traditional pattern of investing in preexisting incubator companies, deciding instead to launch their own, relying on meticulous and exhaustive selection of their intellectual property assets, management teams and business plans. [15] With these steps, the funds have been able to accumulate a significant number of success stories, in which they have been 
able to sell the companies at exorbitant prices after increasing their value with partial clinical advances. Examples include Denali Therapeutics, Jounce Therapeutics, Delinia Pharmaceuticals and Kite Pharma. In August 2018, Kite Pharma was sold to Gilead for US\$11.9 billion after having absorbed repeated investments from various venture capital funds.[13]

Big pharma companies have learned from their bureaucratic limitations in order to coordinate disruptive development programs and have fine-tuned their business models for a more effective approach to biotech firms. To this end, they have set up corporate venture capital funds from which they invest in innovative biotech companies of interest given the complementarity of their intellectual property assets.[17] All in all, they have managed to nurture and coordinate a decentralized, agile development program outside the influence of internal vertical structures.

Three of these funds were established from 1970 to 2000 (Johnson \& Johnson, Glaxo SmithKline, and Novartis),[17] but many more began to spring up in the new millennium. Through 2011 another nine were founded (by Astra Zeneca, Roche, Pfizer, Novartis, Boehringer Ingelheim, Merck, and three by Eli Lilly), with US\$100 to 500 million invested in each case.[17]

Another resource successfully explored by big pharma is the creation of what is known as quasi-public institutions, which involves pharma industry acquisition of the majority of public shares (listed on a stock exchange) of successful medium- to large-sized biotech firms with several profitable products on the market. In this way, a pharmaceutical giant can control the most important companies in the emerging biotech sector without purchasing them outright or constraining their autonomy, therefore preserving their robust scientific productivity. One example is Genentech-Roche, where Genentech's corporate independence has survived the purchase of all its shares by Roche.[18]

Resilience, adaptation and change: challenges and opportunities for Cuba's biotechnology sector While the current context for the industry's global development poses challenges for the future of biotechnology in Cuba, it also provides opportunities, given the strengths demonstrated by this sector in the country.

Cuba's biotech industry was launched in 1981, just a few years after the first biotech company in the USA (Genentech, 1976). From the start, the fledgling industry has enjoyed strong financial support from government, which bet on the rigor and audacity of its innovation, as well as its ability to contribute to population health in Cuba. The sector is characterized by early dedication to completing the product development cycle, taking a product from laboratory to market, thus converting science into business while responding to health problems through prompt introduction of results in the country's national health service.

All this fostered the relatively rapid advance toward overall profitability of Cuba's biotech system as a set of companies, generating exports and positively impacting various health indicators in the country. Today, a total of 34 research/production/marketing facilities employing more than 20,000 workers are brought together under the BioCubaFarma holding company. More than 700 products have been registered in Cuba and abroad, exports are sold to 49 countries, and more than 400 products are in various stages of the R\&D pipeline. Chronic as well as infectious diseases are targeted for novel product development as well as biosimilars for domestic use.[19]

Another of Cuban biotech's strengths continues to be integration with the country's universities, public health system and informatics/telecommunications industries, which can accelerate early development of R\&D programs and reduce costs. At the same time, Cuban firms have experience interacting with pharmaceutical companies and entering into intellectual property licensing agreements abroad.

Yet, challenges abound, beginning with the external context, involving changes identified earlier in the financing arrangements for the industry globally, as well as in the particular context faced by Cuba's biotechnology and economy at this juncture.

For example, from 2005 to 2015, the country's biotech export capacity was reinforced through complementary economic agreements between Cuba and various Latin American governments.[20] However, regional changes in recent years have undermined the industry's self-financing capacity, and Latin America's unstable political context has had a negative impact on the natural market for Cuban biotech products. This has been exacerbated by the US administration's escalation of economic sanctions and hostilities towards Cuba, aimed at torpedoing investment, trade and financial operations.[21] Cuba's minimal economic growth during the period has shifted government financial priorities toward shorter-term investments such as real estate and tourism.

Further complicating this situation is the proliferation of barriers to development and registration of new products due to growing data requirements for regional regulatory filing. $[22,23]$ Altogether these factors make it essential for the Cuban biotech sector to adapt to the new environment: engaging alternative financing sources for innovation, and new product development is of strategic importance for the sector's future.

To accomplish this, a number of steps must be taken. One is for Cuban biotechnology to redesign its R\&D programs to mitigate risk and facilitate access to funding sources. This means it should set priorities in its projects portfolio, sacrificing some projects to reserve funds for those most likely to succeed, and should also hold off on negotiations until more advanced stages when products have gained greater value.

These changes will require new policies that favor the ability to rapidly identify and seize marketplace opportunities, which will both attract capital and stimulate innovation within the hightech sector, in addition to allowing more freedom in assuming risk to compete in the international marketplace. After all, the best way to mitigate risk is not to avoid it at all costs, but to try to understand and navigate it as intelligently as possible. Recently, new business models are being explored that should allow more dynamic access to foreign capital for developing innovative biotech projects and achieving their insertion in more competitive markets. 
Historically, several Cuban biotech companies have been able to move toward profitability based on exports to the Global South.[20] While income is insufficient to finance clinical development of their products in high-income countries, the operational profitability in the South can offer the financial guarantees necessary to attract venture capital.

The new context requires adopting flexible business models and adapting the industry's discourse to attract new interest from venture capital funds, since these usually invest in companies rather than projects or technologies.[24]

One example demonstrates the feasibility of attracting such capital for Cuba's intangible biotech assets. In October, 2018, the US company Equillium earned US\$65 million in revenues when it offered a portion of its shares for sale on Nasdaq. At that time, Equillium had a single intangible asset: marketing rights in the USA and Canada for Itolizumab, developed and patented by Cuba's Molecular Immunology Center (CIM) and sublicensed to Equillium by Biocon, CIM's Indian licensee.[25]

Indirect investment, including venture capital, could be transformed into direct investment in Cuban biotech companies if a more flexible and less risk-averse legal framework were put in place for the sector, reflecting policies aimed at longer-term profitability. All of these changes are necessary to foster a successful and sustainable future for Cuban biotechnology, building upon nearly 40 years of experience, intellectual capacity, business acumen and scientific innovation. $-1 /$ -

\section{REFERENCES}

1. Walsh G. Biopharmaceutical benchmarks 2018 . Nat Biotechnol. 2018 Dec 6;36(12):1136-45

2. Evens R, Kaitin K. The evolution of biotechnology and its impact on health care. Health Aff (Millwood). 2015 Feb;34(2):210-9.

3. Thakor RT, Anaya N, Zhang Y, Vilanilam C, Siah $\mathrm{KW}$, Wong $\mathrm{CH}$, et al. Just how good an investment is the biopharmaceutical sector? Nat Biotechnol. 2017 Dec;35(12):1149-57.

4. Pisano GP. Can science be a business? Lessons from biotech. Harv Bus Rev. 2006 Oct;84(10):114-24, 150.

5. Stern S. Incentives and focus in university and industrial research: the case of synthetic insulin. In: Rosenberg N, Gelijns AC, Dawkins H, editors. Sources of Medical Technology: Universities and Industry. Washington, DC: National Academy of Sciences; 1995. p. 157-88.

6. Schiff L, Murray F. Biotechnology financing dilemmas and the role of special purpose entities. Nat Biotechnol. 2004 Mar;22(3):271-7.

7. Ford D, Nelsen B. The view beyond venture capital. Nat Biotechnol. 2014 Jan;32(1):15-23.

8. EY.com. Biotechnology Report 2017. Beyond borders: staying the course [Internet]. London: Ernst \&Young; 2017 [cited 2019 Mar 19]. 100 p. Available from: https://www.ey.com/Publica tion/vwLUAssets/ey-biotechnology-report-2017 -beyond-borders-staying-the-course/\$FILE/ ey-biotechnology-report-2017-beyond-borders -staying-the-course.pdf

9. Prasad V, Mailankody S. Research and development spending to bring a single cancer drug to market and revenues after approval. JAMA Intern Med. 2017 Nov 1;177(11):1569-75.

10. Paul SM, Mytelka DS, Dunwiddie CT, Persinger $\mathrm{CC}$, Munos BH, Lindborg SR, et al. How to improve R\&D productivity: the pharmaceutical in- dustry's grand challenge. Nat Rev Drug Discov. 2010 Mar;9(3):203-14.

11. Thomas DW, Burns J, Audette J, Carroll A, Dow-Hygelund C, Hay M. Clinical development success rates 2006-2015. San Diego: Biomedtracker; 2016 Jun. 28 p.

12. Wong $\mathrm{CH}$, Siah KW, Lo AW. Estimation of clinical trial success rates and related parameters. Biostatistics. 2019 Apr 1;20(2):273-86.

13. Morrison C, Lähteenmäki R. Public biotech in 2017-the numbers. Nat Biotechnol. 2018 Jul 6;36(7):576-84

14. Morrison C, Lahteenmaki R. Public biotech 2018-the numbers. Nat Biotechnol. 2019 Jul;37(7):714-21.

15. Huggett B. Bringing up baby. Nat Biotechnol. 2018 May 9;36(5):393-401.

16. Kumar-Sinha C, Chinnaiyan AM. Precision oncology in the age of integrative genomics. Nat Biotechnol. 2018 Jan 10;36(1):46-60.

17. McCammon MG, Pio E, Barakat S, Vyakarnam S. Corporate venture capital and Cambridge. Nat Biotechnol. 2014 Oct;32(10):975-8.

18. Times TNY. Roche Agrees to Buy Genentech for \$46.8 Billion. The New York Times [Internet]. 2009 Mar 12 [cited 2019 Mar 19]; World Business. Available from: https://www.nytimes.com/2009/03/13/ business/worldbusiness/13drugs.html.

19. Grupo de las Industrias Biotecnológica y Farmacéutica de Cuba. BioCubaFarma [Internet]. Havana: BioCubaFarma, c2019 [cited 2019 Jun 4]. Available from: https://www.biocubafarma.cu. Spanish.

20. World Health Organization [Internet]. Geneva: World Helath Organization; c2019. Publications. Cuban experience with local production of medicines, technology transfer and improving access to health [Internet]. Geneva: World Helath Organization; 2015.80 p. Available from: https://www .who.int/phi/publications/cuban_experience local prod medstech transfer/en/

21. Ministry of Foreign Affairs (CU). Informe de Cuba sobre la Resolución 73/8 de la Asamblea General de las Naciones Unidas. "Necesidad de poner fin al bloqueo económico, comercial y financiero impuesto por los Estados Unidos de América contra Cuba". Havana: Ministry of Foreign Affairs (CU); [Internet]. 2019 Jul [cited 2019 Nov 6] Available from: http://www.minrex.gob.cu/sites/ default/files/2019-09/Cuba\%20vs\%20Bloqueo .pdf. Spanish.

22. Alemayehu C, Mitchell G, Nikles J. Barriers for conducting clinical trials in developing countries-a systematic review. Int J Equity Health. 2018 Mar 22;17(1):37

23. García R, Araujo DV. The regulation of biosimilars in Latin America. Curr Rheumatol Rep. 2016 Mar;18(3):16.

24. Ben-Joseph O. Where the bodies lie. Nat Biotechnol. 2016 Sep 8;34(9):909-11.

25. Nasdaq [Internet]. New York: Nasdaq; c2019. Markets Equillium prices IPO at \$14, the low end of the range; 2018 Oct 12 [cited 2019 Jun 21]. Available from: https://www.nasdaq.com/article/ equillium-prices-ipo-at-14-the-low-end-of-the -range-cm 1036324

\section{THE AUTHOR}

Einard Blanco-García (einard@cimab.cu), biotechnologist with a master's degree in drug technology and quality control, CIMAB S.A., Havana, Cuba.

Submitted: July 4, 2019

Approved for publication: January 16, 2020

Disclosures: None 